\title{
उMR
}

\section{High yield of functional metagenomic library from mangroves constructed in fosmid vector}

\author{
A.C.S. Gonçalves, A.C.F. dos Santos, T.F. dos Santos, T.B.A. Pessoa, \\ J.C.T. Dias and R.P. Rezende \\ Departamento de Ciências Biológicas, Universidade Estadual de Santa Cruz, \\ Ilhéus, BA, Brasil \\ Corresponding author: R.P. Rezende \\ E-mail: rezende.rachel@gmail.com
}

Genet. Mol. Res. 14 (4): 11841-11847 (2015)

Received May 27, 2015

Accepted July 23, 2015

Published October 2, 2015

DOI http://dx.doi.org/10.4238/2015.October.2.17

\begin{abstract}
In the present study, metagenomic technique and fosmid vectors were used to construct a library of clones for exploring the biotechnological potential of mangrove soils by isolation of functional genes encoding hydrolytic enzymes. The library was built with genomic DNA from the soil samples of mangrove sediments and the functional screening of 1824 clones ( 64 Mbp) was performed to detect the hydrolytic activity specific for cellulases, amylases (at acidic, neutral and basic $\mathrm{pH}$ ), lipases/esterases, proteases, and nitrilases. Significant numbers of clones, positive for the tested enzyme activities were obtained. Our results indicate the importance and biotechnological potential of mangrove soils especially when compared to those obtained using other soil metagenomic libraries.
\end{abstract}

Key words: Hydrolytic enzymes; Metagenomics; Mangrove; Fosmids 


\section{INTRODUCTION}

Microorganisms found in mangroves have a fundamental role in the biochemical transformation of nutrients and are essential for degradation of organic matter. However, studies on the structure and function of bacterial communities in mangrove soil are still limited and more information is needed for a better understanding of their ecological role (Kathiresan and Bingham, 2001; Santos et al., 2014). Adaptations of these microorganisms in the most diverse environments can often result in the production of bioactive compounds and enzymes required for their development. Such compounds are also useful in many industrial and biotechnological processes (Singh, 2009; Zhou et al., 2015). The most important industrial enzymes are of microbial origin; therefore, screening for new microbial enzymes is important for the development of new industrial processes (Singh, 2009; Uchiyama and Miyazaki, 2009).

Metagenomics is a technique that is being used to isolate genes encoding new enzymes from environmental samples, which are, otherwise, difficult to obtain from traditional cultivation of microorganisms (Daniel, 2005). The functional screening of metagenomic libraries evaluates for the presence of enzymes, such as proteases and amylases or attributes of a metabolite having cosmetic and antimicrobial properties (Ferrer et al., 2009). The disadvantage in functional screening is the need for evaluation of thousands to hundreds of thousands clones for a specific function. Alternatively, it is possible to use large insert vectors like fosmids as carriers that allow the construction of metagenomic libraries with lower number of clones and higher success rate in isolation of genes encoding for new enzymes, identification of complete metabolic pathways, bioactive compounds, and polycistronic genes (Daniel, 2005; Kim et al., 2009; Ferrer et al., 2009).

This study was aimed to construct a metagenomic library from the total DNA extracted from mangrove soil samples in fosmid vector and to perform functional screening for clones demonstrating hydrolytic activities such as lipase/esterase, cellulase, amylase, protease, and nitrilase/hydrolase. The results were compared to those obtained in other soil metagenomic libraries and are critically discussed here to highlight the biotechnological potential of mangrove soils as important natural seed banks for hydrolytic enzymes.

\section{MATERIAL AND METHODS}

\section{Soil samples}

Five mangrove soil samples were collected from Camamu Bay, located on the southern coast of Bahia (local $1=13^{\circ} 93^{\prime}$ 94.8" S, 39 06' 89,4" W; local 2 = 13 93' 53.1" S, 39 5' 7.4" W; local $3=13^{\circ} 92^{\prime} 31.5^{\prime \prime} \mathrm{S}, 39^{\circ} 5^{\prime}$ 32" W; local $4=13^{\circ} 90^{\prime} 71.5$ "S, 39 $4^{\prime}$ ' 96.7" W; local $5=13^{\circ} 89^{\prime}$ $\left.46.7^{\prime \prime} \mathrm{S}, 39^{\circ} 3^{\prime} 88^{\prime \prime} \mathrm{W}\right)$. The samples were placed in sterile plastic bags on wet ice and transported immediately to the laboratory for DNA extraction (Santos et al., 2014).

\section{DNA extraction and metagenomic library construction}

DNA extraction was performed using the PowerMax Soil DNA Isolation Kit (MOBIO Laboratories, Carlsbad, CA, USA) following the manufacturer recommended protocol. Equal concentrations of the purified DNA obtained from different soil samples were pooled and a metagenomic library was prepared in fosmid pCC2FOS using the CopyControl ${ }^{\mathrm{TM}}$ HTP fosmid 
library production kit (Epicentre, Madison, WI, USA), following the recommendations of the manufacturer. Briefly, the 4 steps involved in the process were: 1) repair and selection of fragments of the purified DNA 35-45 kb in size; 2) ligation of the DNA fragments in the pCC2FOS fosmids and their packaging in phage lambda; 3) transformation in Escherichia coli EPI300 by infecting with the phage lambda; and 4) collection and storage of the transformants. The cloned library was stored at $-80^{\circ} \mathrm{C}$ in Luria-Bertani (LB) broth supplemented with $12.5 \mu \mathrm{g} / \mathrm{mL}$ chloramphenicol and $25 \%$ glycerol (Pessoa et al., 2013). All the clones obtained were screened for the presence of hydrolytic enzymes.

\section{Selection of clones with hydrolytic activities}

Screening for hydrolytic enzymes was based on the inoculation of each clone in a complex medium containing specific organic substrates. Colonies showing activities for the substrates of interest were selected for further studies. Modified LB agar (modified LA) (containing no $\mathrm{NaCl}$ and decreased concentrations of peptone and yeast extract) was used to stimulate the expression of hydrolases (Sambrook, 1989). The enzymatic substrates used in this study were: $1 \%$ skimmed milk for proteases (Sambrook, 1989; Jones et al., 2007; Figure 1A); 0.2\% carboxymethyl cellulose for cellulase (Teather and Wood, 1982; Figure 1B); 1\% tributyrin for lipases/esterases (Kim et al., 2009; Faoro et.al., 2012; Figure 1C); 1\% starch, pH 4.7 and pH 10 for amylases (Lorenz and Schleper, 2002; Figure 1D), and $\mathrm{M} 9$ agar medium $\left(0.1 \mathrm{mM} \mathrm{CaCl}_{2}, 1 \mathrm{mM} \mathrm{MgSO}_{4}, 0.2 \%\right.$ glucose, and $1.3 \%$ agar) supplemented with $10 \mathrm{mM}$ acetonitrile (as the sole nitrogen source) for nitrilases/hydrolases. Chloramphenicol (12.5 $\mu \mathrm{g} / \mathrm{mL}$ ) was used in all screening media for selective isolation and growth of clones containing the inserted fosmids. Activities of all the positive clones (colonies showing a "halo" indicative of hydrolysis or enzymatic activities) were tested in triplicate to eliminate false-positive results.
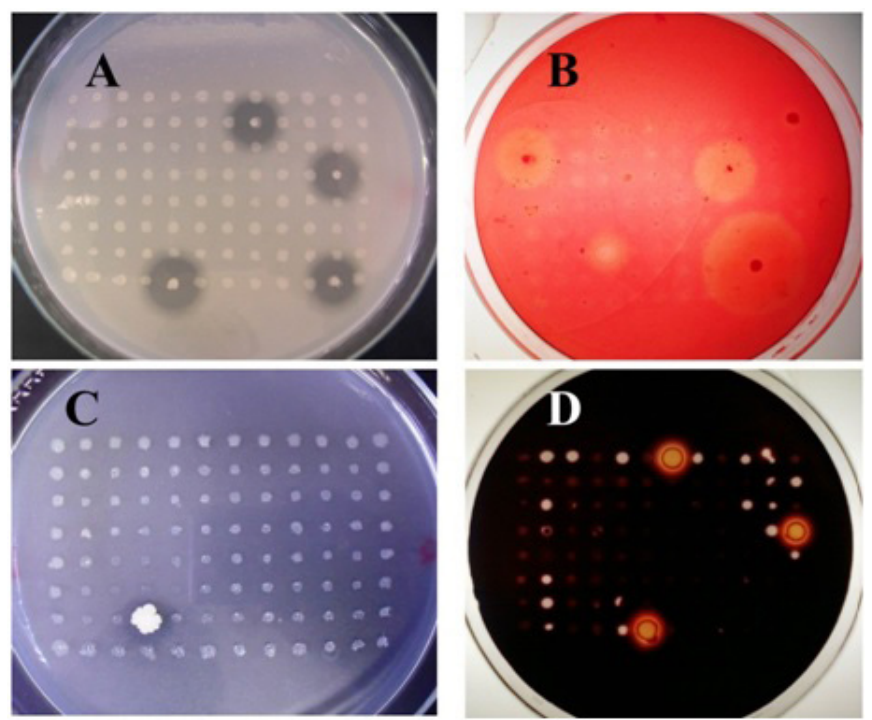

Figure 1. Plates containing selective medium and metagenomic mangrove clones with hydrolysis positive. A. Hydrolysis halos visible in LA milk medium containing positive clones. B. Hydrolysis halos in selective medium carboxymethyl cellulase stained with solution Congo red. C. Medium LA with $1 \%$ Tributyrin, containing positive clone. D. LA medium starch, stained with iodine solution, containing positive clones. 


\section{RESULTS AND DISCUSSION}

\section{DNA extraction and metagenomic library construction}

The electrophoresis of the extracted DNA revealed an intense band above $36 \mathrm{~kb}$, indicating a high molecular weight DNA (Figure 2), which is ideal for the construction of metagenomic libraries. Construction of fosmid metagenomic library yielded 1824 clones, a number lower than expected, but considerably sufficient for performing functional screening.

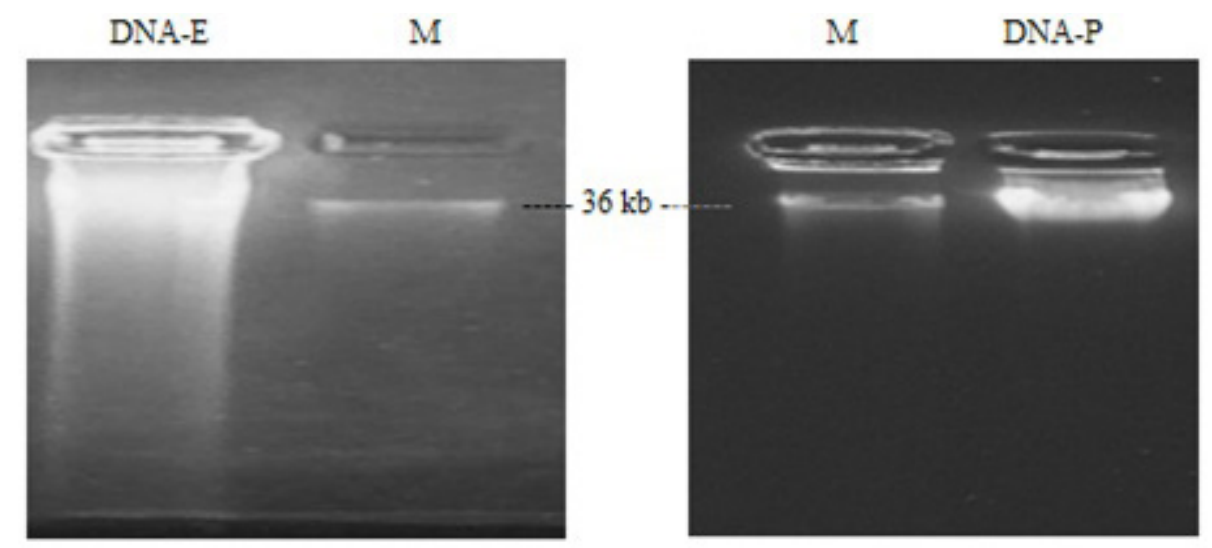

Figure 2. Agarose gel electrophoresis of DNA extraction from mangrove sediment and DNA purification. $\mathrm{M}=$ molecular weight markers; DNA-E = extract DNA; DNA-P = purified DNA. DNA was stained with SYBR Green.

The fosmid library containing single-copy inserts of about $40 \mathrm{~kb}$ were stored on 96 -well plates at $-80^{\circ} \mathrm{C}$. The insert size is an important attribute in the construction of metagenomic libraries. Large 30-50-kb-sized DNA inserts may contain several polycistronic genes, which may lead to the possibility of identification of complete metabolic pathways (Daniel, 2005). This suggests that the relatively low number of clones in the library did not influence the cloning of genes with high biotechnological potential, since the quality of DNA extracted from the mangrove soil was good, produced the inserts of approximately $40 \mathrm{~kb}$ and the ligation of the inserts was efficient.

\section{Functional screening}

Comparing the approximate number of bases ( $64 \mathrm{Mbp})$ to the average genome size of a soil bacterium ( 4 Mbp) (Liles et al., 2003; Santos et al., 2014), it can be estimated that the library generated in the present study could screen about 16 prokaryotic genomes. Interestingly, despite the fact that the use of fosmid system for functional screening may present some disadvantages only genes recognized by the expression system are detected. Our library contained several clones harboring genes encoding for hydrolytic enzymes, i.e., six positive clones for nitrilases, 5 for proteases, 3 for amylases, 1 for cellulases, and 7 clones for lipases/esterases were identified. Our screen for hydrolytic activities yielded 1.15 positive clones per 100 clones analyzed. Such high efficiency may reflect a high diversity and abundance of hydrolytic enzymes in tropical mangrove soils. However, despite numerous studies on microbial diversity in mangrove ecosystems (Gomes et al., 2011) there is a lack in the studies of their functional (metabolic) diversity. 
The species richness of microbial communities in mangrove has been demonstrated in several studies based on cultivation independent approaches (denaturing gradient gel electrophoresis and pyrosequencing; Gomes et al., 2011; Andreote et al., 2012). We believe that the choosing large inserts $(35-40 \mathrm{~kb})$ for cloning in the fosmid vectors and the wealth of microorganisms in the mangrove environment were essential factors that contributed to a high number of positive clones manifesting different hydrolytic enzyme activities. Several vectors are available for cloning of large DNA fragments. Fosmid inserts are most commonly used to construct metagenomic libraries, because, although they may result in a small number of clones, they nevertheless aggregate more genes of interest, without these genes being fragmented. This increases the chances of polycistronic genes being inserted into the vector, thus, maximizing the opportunity for the detection of functional genes (Terrón-González et al., 2013). In future, library of clones can be sequenced, to identify particular functional genes of interest. Our study employed functional analysis of metagenome, through the screening of the metagenomic library clones on solid medium containing specific substrates, enabling us to isolate functional genes. The metagenomic library generated in this study had a lower number of clones, compared with other functional metagenomic libraries (Table 1), yet we found a large number of positive clones for hydrolysis of five different substrates (tributyrin for lipases/esterases, skimmed milk for proteases, carboxymethyl cellulose for cellulase, starch for amylases, and acetonitrile as sole nitrogen source for nitrilases/hydrolases) commonly used in industry. In concurrence with our observations, Andreote et al. (2012) demonstrated high occurrences of sequences that may be related to energy metabolism, metabolism of cofactors and vitamins, carbohydrate metabolism, and metabolic transformation of carbon, nitrogen, and sulfur in mangrove sediments. Together with their findings, our results provide the evidence that mangroves may comprise important reservoirs of hydrolytic enzymes for biotechnological purposes.

Table 1. Comparison screening of metagenomic libraries in soil or marine sediment

\begin{tabular}{|c|c|c|c|c|c|c|c|}
\hline Enzymatic activity & Reference & Sample & Total clones & Insert size $(\mathrm{kb})$ & Bases (Mbp) & Positive clones & $\%$ \\
\hline \multirow[t]{3}{*}{ Amylase } & Henne et al., 2000 & Soil & 3,648 & 27 & 98.5 & 27 & 0.219 \\
\hline & Yang et al., 2012 & Marine sediments & 20,000 & 35 & - & 1 & 0.005 \\
\hline & This study & Mangrove sediments & 1,824 & 40 & 63.84 & 3 & 0.164 \\
\hline \multirow[t]{3}{*}{ Cellulase } & Voget et al., 2006 & Soil $^{*}$ & 1,700 & 22 & 37.4 & 8 & 0.471 \\
\hline & Berlemont et al., 2009 & Antarctic soil & 10,000 & 5 & 63.6 & 11 & 0.110 \\
\hline & This study & Mangrove & 1,824 & 40 & 63.84 & 1 & 0.055 \\
\hline \multirow[t]{4}{*}{ Lipase } & Uchiyama and Miyazaki, 2009 & Soil & 67,000 & 8 & 536.0 & 98 & 0.146 \\
\hline & Uchiyama and Miyazaki, 2009 & Soil & 19,968 & 40 & 798.7 & 47 & 0.235 \\
\hline & Faoro et al., 2012 & Forest & 29,280 & 35 & 1024.8 & 92 & 0.314 \\
\hline & This study & Mangrove & 1,824 & 40 & 63.84 & 7 & 0.384 \\
\hline \multirow[t]{2}{*}{ Nitrilase } & Bayer et al., 2011 & Soil $^{*}$ & 3.79 million & - & - & 9 & 0.000 \\
\hline & This study & Mangrove & 1,824 & 40 & 63.84 & 6 & 0.329 \\
\hline \multirow[t]{3}{*}{ Protease } & Gupta et al., 2002 & Soil & 100,000 & 10 & 1000.0 & 1 & 0.001 \\
\hline & Biver et al., 2013 & Soil & 35,000 & 12 & 665.0 & 1 & 0.002 \\
\hline & This study & Mangrove & 1,824 & 40 & 63.84 & 4 & 0.219 \\
\hline
\end{tabular}

Enriched library (*); undisclosed (-).

\section{CONCLUSION}

The results obtained in the present study demonstrated that a relatively small effort devoted to construct a mangrove soil metagenomic library (1824 clones) could allow us to isolate genes encoding for cellulases, amylases at acidic, neutral, and basic $\mathrm{pH}$, lipases/esterases, proteases, and nitrilases. It further provides evidence that soil matrices of tropical mangroves have 
the potential to be a rich natural 'seed bank' for isolation of genes encoding hydrolytic enzymes of industrial relevance. Probably, a diverse range of organic substances deposited in mangroves have a strong influence on the microbiological diversity, which makes this environment an interesting candidate for employing more sophisticated approaches for the search of new catalytic enzymes that could be useful for industrial and biotechnological applications.

\section{ACKNOWLEDGMENTS}

Research supported by Conselho Nacional de Pesquisa e Desenvolvimento (CNPq, \#558272/2009-6) and Fundação de Amparo à Pesquisa do Estado da Bahia (FAPESB) scholarship grants to A.C.S Gonçalves).

\section{REFERENCES}

Andreote FD, Jiménez DJ, Chaves D, Dias AC, et al. (2012). The Microbiome of Brazilian mangrove sediments as revealed by metagenomics. PLoS One 7. Doi: 10.1371/journal.pone.0038600.

Bayer S, Birkemeyer C and Ballschmiter M (2011). A nitrilase from a metagenomic library acts regioselectively on aliphatic dinitriles. Appl. Microbiol. Biotechnol. 89: 91-98.

Berlemont R, Delsaute M, Pipers D, D'Amico S, et al. (2009). Insights into bacterial cellulose biosynthesis by functional metagenomics on Antarctic soil samples. ISME J. 3: 1070-1081.

Biver S, Portetelle D and Vandenbol M (2013). Characterization of a new oxidant-stable serine protease isolated by functional metagenomics. SpringerPLus 2: 410. Doi: 10.1186/2193-1801-2-410.

Daniel R (2005). The metagenomics of soil. Nat. Rev. Micro 3: 470-478.

Faoro H, Glogauer A, Couto GH, de Souza EM, et al. (2012). Characterization of a new Acidobacteria-derived moderately thermostable lipase from a Brazilian Atlantic Forest soil metagenome. FEMS Microbiol. Ecol. 81: 386-394.

Ferrer M, Beloqui A, Timmis KN and Golyshin PN (2009). Metagenomics for mining new genetic resources of microbial communities. J. Mol. Microbiol. Biotechnol. 16: 109-123.

Gomes NC, Cleary DF, Calado R and Costa R (2011). Mangrove bacterial richness. Communicative Integr. Biol. 4: 1-5.

Gupta R, Berg QK and Lorenz P (2002). Bacterial alkaline proteases: molecular approaches and industrial applications. Appl. Microbiol. Biotechnol. 59: 15-32.

Henne A, Schmitz RA, Bomeke M, Gottschalk G, et al. (2000). Screening of environmental DNA libraries for the presence of genes conferring lipolytic activity on Escherichia coli. Appl. Environ. Microbiol. 66: 3113-3116.

Jones BV, Sun F and Marchesi JR (2007). Using skimmed milk agar to functionally screen a gut metagenomic library for proteases may lead to false positives. Lett. Appl. Microbiol. 45: 418-420.

Kathiresan K and Bingham BL (2001). Biology of mangroves and mangrove Ecosystems. Adv. Mar. Biol. 40: 81-251.

Kim EY, Oh KH, Lee MH, Kang CH, et al. (2009). Novel cold adapted alkaline lipase from an intertidal flat metagenome and proposal for a new family of bacterial lipases. Appl. Environ. Microbiol. 75: 257-260.

Liles MR, Manske BF, Bintrim SB, Handelsman J, et al. (2003). A census of rRNA genes and linked genomic sequences within a soil metagenomic library. Appl. Environ. Microbiol. 69: 2684-2691.

Lorenz P and Schleper C (2002). Metagenome - a challenging source of enzyme discovery. J. Mol. Catalysis B Enzymatic 19-20, 13-19.

Pessoa TB, de Souza SS, Cerqueira AF, Rezende RP, et al. (2013). Construction and validation of metagenomic DNA libraries from landfarm soil microorganisms. Genet. Mol. Res. 12: 2148- 2155.

Sambrook J, Fritsch EF and Maniatis T (1989). Molecular cloning: a laboratory manual. 2nd edn. Cold Spring Harbor Laboratory Press, Cold Spring Harbor.

Santos AC, Rezende RP, Brendel M, Souza SS, et al. (2014). Evaluation of the biodegradability of petroleum in microcosm systems by using mangrove sediments from Camamu Bay, Bahia, Brazil. Genet. Mol. Res. 13: 2048-2059.

Singh BK (2009). Exploring microbial diversity for biotechnology: the way forward. Trends Biotechnol. 28: 111-116.

Teather RM and Wood PJ (1982). Use of Congo red-polysaccharide interactions in enumeration and characterization of cellulolytic bacteria from the bovine rumen. Appl. Environ. Microbiol. 43: 777-780.

Terrón-González L, Medina C, Limón-Mortés MC and Santero E (2013). Heterologous viral expression systems in fosmid vectors increase the functional analysis potential of metagenomic libraries. Sci. Rep. 3: 1107. Doi: 10.1038/srep01107.

Uchiyama T and Miyazaki K (2009). Functional metagenomics for enzyme discovery: challenges to efficient screening. Curr. 
Opin. Biotechnol. 20: 616-622.

Voget S, Steele HL and Streit WR (2006). Characterization of a metagenome-derived halotolerant cellulase. J. Biotechnol. 126: 26-36.

Yang L, Yin L, Zhang X, Gao Y, et al. (2012). Identification and Phylogenetic Characterization of a New Subfamily of a-Amylase Enzymes from Marine Microorganisms. Mar. Biotechnol. 14: 253-260.

Zhou J, He Z, Yang Y, Deng Y, et al. (2015). High-Throughput Metagenomic Technologies for Complex Microbial Community Analysis: Open and Closed Formats. 6: 1-17. Doi: 10.1128/mBio.02288-14. 